\title{
La influencia del contexto intelectual, artístico y literario en el Schlager de la República de Weimar
}

\author{
Juan-Fadrique Fernández Martínez \\ Universidad de Sevilla \\ jufadri@gmail.com
}

https://dx.doi.org/10.12795/futhark.2013.i08.07

\begin{abstract}
The German Schlager reached one of its peaks in the nineteen twenties. The democratic regime between the First World War and Hitler's takeover of power, with its controversial intellectuals, its vigour and creativity within all artistic genres, the birth of new literary trends, appearance of new fashion as well as the implantation of mass culture, consequently led to the genre of Schlager songs and its popularity. This actual work has included trawling through the many lyrics of these songs to show the influence of its time in the intellectual, artistic and literary context. This golden age of the Schlager coincides with the inflation in 1923, the world economic crisis in 1929 , and the release of the sound movies and finally it slowed down with the Nazi takeover of political power. Whereas the majority of the songs do not participate with much cultural value in the sense that did for instance the theatres in Berlin at the time, other songs show a taste for the playful type Dadaist and others again amuse with a more spicy text. All in all they include a great variety of song lyrics which favourably enriches the genre of the German popular song.

Key words: German popular music, Schlager, Roaring Twenties, Jazz Age, Weimar Germany

Resumen: El Schlager alemán alcanzó en los años veinte una de sus cimas. El régimen democrático entre la primera guerra mundial y la llegada al poder de Hitler con sus contradicciones intelectuales, su exuberancia creativa en todos los órdenes artísticos, el surgimiento de nuevas corrientes literarias, la aparición de nuevas modas así como la implantación de la cultura de masas, trajo consigo en lo concerniente a la música popular el desarrollo del género y su popularización. El presente trabajo rastrea entre los muchos textos aquellos que muestran la influencia del contexto intelectual, artístico y literario. Este período dorado de la música comercial alemana coincide con
\end{abstract}


el periodo de la inflación (1923), con la crisis económica mundial (1929), con el éxito de las películas sonoras y fue finalmente frenado con la toma del poder de los nazis. Los textos mostrados se alejan en muchos casos de los condicionamientos históricos cercanos, a veces con excéntrico humor e ironía, otras veces proponen frente a la insatisfacción cotidiana, la ensoñación amorosa, cuando no el refugio o la huida a paraísos más o menos cercanos, la música y el baile también invitaban a ello. Aunque la mayoría de las canciones no participan de una exigencia cultural otras como el teatro berlinés sí lo hicieron. Otros muestran el gusto por el disparate tipo dadaísta y otros se conformaron con una lectura picante. En conjunto todo un abanico de posibilidades lo que redundó en el beneficio del género.

Palabras clave: canción comercial alemana, Schlager, los locos años veinte, los felices años veinte, República de Weimar

En general la intelectualidad de la época se aleja del gobierno republicano, aceptado por consideraciones de orden realista a la par que despreciado y criticado. El régimen democrático favoreció una intensísima vida cultural en los años veinte en todos los campos.

A pesar de esta afirmación globalmente aceptada con una visión unitaria de la época objeto de análisis es históricamente esencial distinguir tres fases claramente diferenciadas durante este escenario republicano, que ayudan a entender convenientemente las evoluciones en la temática y en el tono del Schlager alemán o "canción ligera" 1 y por supuesto el contexto sociohistórico en el que surgen y del que a su vez son en mi opinión un constituyente importante: la primera (1919-1924) se caracteriza por la desastrosa inflación, la ocupación militar extranjera, los asesinatos políticos y la sangrienta represión del movimiento espartaquista surgido tras la Revolución de Octubre; la segunda fase (1925-1929) viene determinada por la estabilidad financiera, la prosperidad económica y la mejora en las relaciones con el extranjero; en la tercera fase (1929-1933) los rasgos más significativos son los fuertes efectos de la

1 Otras traducciones posibles para el término alemán Schlager serían "canción de consumo" o "canción comercial". De todas maneras en esta época las canciones que entran bajo este género son mayoritariamente canciones bailables. El concepto entraría dentro de la categoría de leichte Musik (vs.ernste Musik), y por tanto perteneciente a la baja cultura. El problema sociológico surge cuando con la invención del disco y del gramófono, con la producción industrial de éstos, con la creciente asequibilidad del producto y su difusión a través de las ondas radiofónicas, el consumo de música reproducida se convierte en asunto de masas. Cfr. Para este tema Ecco, Umberto, Apocalípticos e integrados, Barcelona, Tusquets, 1995, págs. 287-298. Asimismo sobre el uso de etiquetas que los monopolios capitalistas de la industria del sonido usan (seria, ligera, romántica, étnica, culta, etc.) cfr.ARGELIERS, León, "La música como mercancía” en GómEZ, Zoila (ed.), Musicología en Latinoamérica, La Habana, PE, 1984, pág. 420.

Futhark 8 (2013) Fernández, La influencia del contexto intelectual, 127-151 ISSN 1886-9300 
crisis económica mundial, el desempleo, la disolución de partidos de clase media y la violencia política del partido nacionalsocialista.

Los años inmediatamente posteriores a la guerra fueron un período de fervor intelectual como consecuencia de la experiencia bélica, de la Revolución de Octubre y de la progresiva desaparición de restricciones y censuras pasadas. La guerra deja sensación de ansiedad, frenesí y exuberancia creativa, mezcla de cinismo y confianza, de irreverencia hacia las tradiciones. Destacan sobre todo en música Hindemith y Krĕnek, junto a K. Weil y $\mathrm{B}$. Brecht que impulsan el teatro político y el cabaret en Alemania.

Es también una época donde junto a la inestabilidad política social y económica, se instauran importantes innovaciones técnica y mediáticas. La radio y el cine sonoro comienzan su expansión, y Berlín es indiscutiblemente el centro político y cultural de Alemania. Es la época que se viene conociendo con razón o sin ella como los GoldeneZwanziger o die wilden Zwanziger, donde las grandes ciudades con sus locales de diversión y teatros brillan, y donde se escuchan primero las viejas melodías y luego los nuevos ritmos.

Desde luego el comienzo era nefasto: la miseria de la posguerra, la pérdida de un octavo de su territorio, las elevadas reparaciones de guerra y las condiciones de paz impuestas a la República como estado continuador del Imperio Alemán en Versailles por los vencedores fueron muy duras. Los fascistas alemanes se referirán a este acuerdo como Schandvertrag, otorgándoles argumentos para el rearme y para una política de agresión.

A modo de ejemplo señalaré que incluso en la denomina Dollarzeit (1925-1926) un Schellackplatte (traducible al español como disco de pizarra, aunque en realidad era prensado sobre goma laca) costaba $3,75 \mathrm{RM}^{2}$ mientras que un litro de leche costaba 32 peniques, lo que suponía un verdadero lujo para una familia trabajadora cargada de niños, por no mencionar el precio de un gramófono, ya que el sueldo medio de un trabajador durante el período republicano rondaba los 87,1 peniques por hora y semanalmente recibía un salario bruto de 41,7 marcos. Obviamente los barrios trabajadores disfrutaban poco del brillo de lo moderno, sólo así se puede entender mejor la catástrofe que supuso para las clases trabajadoras la crisis económica mundial. No obstante Berlín era una ciudad tan grande y poliédrica que el visitante bien podía conocer una cara de la misma sin conocer las otras, es decir, la ciudad centro de diversión, la ciudad de los teatros, y no los barrios industriales y periféricos.

2 Abreviatura de Reichsmark, su equivalencia frente al dólar tras la reforma monetaria era de un dólar por 4.20 RM.

Futhark 8 (2013) Fernández, La influencia del contexto intelectual, 127-151 ISSN 1886-9300 
Junto a Berlín destacaron otras ciudades, así en literatura -por citar un ámbito- sobresalieron Múnich, Viena y Praga, pero Berlín se puede tomar como ejemplo porque es la ciudad donde los contrastes se dieron de forma más intensa, a este respecto Otto Friedrich escribió en lo que se convirtió la capital:

"(...) dieses Berlin der zwanziger Jahre mit seinem Sinn für Freiheit und seiner weltstädtischen Lebensauffassungen nach einer so kurzen Blütezeit so gründlich zerstört wurde, (...) zu einer Art Mythos (...), zu einem verlorenen Paradies"3.

A este mismo respecto E.D. Weitz concretiza esa aureola de Berlín con las siguientes palabras:

"Weimar was Berlin, Berlin Weimar. With more than four million residents, the capital was by far the largest city in Germany, the second largest in Europe, a megalopolis that charmed and frightened, attracted and repelled Germans and foreigners alike. In the 1920s it was one of Germany's and Europe's great cultural centers, the home of the Philharmonic, the State Opera, the Comic Opera, scores of theaters, and a cluster of great museums, all located in the center of the city. Berlin was a magnet for artists and poets, the young and ambitious. It had a glittering night club scene, including scores of homosexual bars, and a relentless fascination with the body and sex. Berlin was a great economic machine $(\ldots)^{\prime 4}$.

Al disminuir la hegemonía cultural de Viena después de la guerra Berlín se convirtió a mediados de los años veinte en el centro principal de atracción de todo el área alemana, es el centro cultural del estado. Por el contrario Viena pierde su efervescencia intelectual anterior, aquí el grupo expresionista es destruido por los acontecimientos políticomilitares que llevan a la disolución del Imperio y con él todo el orden social que regía la vida de su capital. Asimismo mueren los representantes de la primera Secesión (Gustav Klimmt y Otto Wagner entre otros) y Schoenberg se marcha a Berlín.

El fracaso de la revolución en occidente tras la guerra y la recuperación del capitalismo mundial determinan el abandono del compromiso social. La teoría estalinista del "socialfascismo» (que identificaba a los socialdemócratas con los fascistas) deja incluso a intelectuales comunistas alejados de la realidad. La tolerancia cultural, el escepticismo y la irreverencia caracterizan los años anteriores al nazismo, sin embargo otros buscan refugio en la fe y en la ortodoxia. Destacan el neomarxismo dogmático de G Lukács, la neoortodoxia religiosa de $\mathrm{K}$. Barth y el movimiento literario Neue Sachlichkeit, como forma de aceptar la reali-

3 FRIEDRICH, Otto, Weltstadt Berlin. Größe und Untergang 1918-1933, Múnich, Kurt Desch Verlag, 1973, pág. 11.

4 WeITZ, Eric D., Weimar Germany. Promise and Tragedy, Princenton, Princenton University Press, 2007, pág. 41

Futhark 8 (2013) Fernández, La influencia del contexto intelectual, 127-151 ISSN 1886-9300 
dad cotidiana, como aproximación objetiva, que deja entrever una actitud de fatalismo y de renuncia a actuar, así como el desprecio por los grandes temas y la exaltación del detalle.

El Existencialismo va a ejercer su influencia en la cultura de los años treinta, sobre todo en la figura de Martin Heidegger, máximo representante en Alemania, que proporcionará respetabilidad filosófica al vulgar irracionalismo nazi. Ya en los veinte había habido anuncios de resignado fatalismo, desilusión y de falta de compromiso.

El gobierno estaba en bancarrota, con frecuencia recurre a las elecciones, la quinta y última vez el 6 de noviembre de $1932^{5}$. El final de este período lo marca el nombramiento de Hitler como canciller por el octogenario presidente von Hindenburg el 30 de enero de 1933.

Desde el punto de vista sociológico considero fundamentales dos características: por un lado la creciente incorporación de la mujer al mundo laboral y por otro la expansión de la industria de ocio que ofrece una amplia gama de posibilidades para el descanso y la diversión (deportes como el fútbol, el ciclismo, el esquí, la natación, el boxeo, la vela o el automovilismo juegan cada vez un papel más importante en la sociedad). Es en esta segunda característica donde se enmarca el desarrollo espectacular que presenta el Schlager, gracias a los nuevos medios técnicos de reproducción que se expanden como son el gramófono y sobre todo la radio y el cine sonoro -a éste último me referiré un poco más adelante-.

La radio sustituye a muchas pequeñas orquestas (Unterhaltungskapellen), mucha gente se queda en casa y baila escuchando la radio. La introducción de la misma en 1923 y su rápida expansión en los años siguientes fue desplazando al Schlager de los salones de baile y del teatro de las capas sociales superiores, para alcanzar a un público mayor. A este respecto habría que rebajar la importancia del disco en los años veinte, puesto que la posesión de un gramófono no era algo ni mucho menos generalizada ${ }^{6}$.

La masificación de la audición musical a través de la radio fundamentalmente y de los nuevos medios de reproducción tuvo hondas repercusiones en la estética musical. Surge la primera industria cultural de la música con características de concentración monopolista y de expan-

5 El 13 de octubre de 1930 los nazis obtuvieron en el Reichstag 107 representantes, convirtiéndose en la segunda fuerza política, el SPD y los comunistas también mejoraron sus resultados. EI NSPD crecía a costa de los nacionalistas alemanes. Los ataques de los camisas pardas a los comercios judíos y a las personas que consideraban judías se convirtieron en moneda corriente. En julio el NSDAP obtuvo 230 parlamentarios, en noviembre retrocedieron situándose en 198 (el SPD 121 y los comunistas 100).

6 BARDONG, Matthias (ed.): Das Lexikon des deutschen Schlagers, Ludwigsburg, Louis, 1992 (2 edic., Mainz, Schott, 1993), pág. 16.

Futhark 8 (2013) Fernández, La influencia del contexto intelectual, 127-151 ISSN 1886-9300 
sión mundial. Se generaliza así el concepto de música utilitaria (Gebrauchsmusik), que con un lenguaje simplificado favorece el consumo de masas y crea productos accesibles a todo el mundo. La tradición del cabaret berlinés ayuda a esta operación cultural, dado que en él se había introducido en los años veinte el jazz. Frente a esto los músicos no pudieron dejar de plantearse el problema de participación en tales proyectos de exigencia cultural (tipo Brecht), enfrentándose a la evolución del lenguaje musical abandonado a la comercialización de productos culturales «deficientes» ${ }^{7}$. Como muestra de ello se produjo la colaboración entre Brecht y Weil.

Por supuesto que la incorporación de la mujer al mundo laboral fue un factor decisivo para favorecer su avance hacia una mayor autonomía y libertad al disponer de ingresos propios. Sin embargo la mayoría de las mujeres que aparecen como protagonistas en el Schlager no representa a la mujer trabajadora, sino a una mujer liberada y ávida de emociones que se corresponde en buena medida con la propia artista que interpreta la canción o mujeres con un estatus socioeconómico semejante. Un ejemplo de mujer trabajadora aparece en la canción "Mein Mädel ist nur eine Verkäuferin" (1930), donde a pesar de las pocas satisfacciones que le da su sueldo a esta joven ("vierzig Mark Gehalt in der Woche") es capaz de otorgarle a su enamorado una gran felicidad ("doch sie gibt mir für viele Millionen Glück!") sobre todo cuando se le acerca amorosamente mientras la Jazzband interpreta su tema favorito.

Es típica la imagen de domingo donde la gente abarrota lugares de ocio como terrazas, parques o playas fluviales (como en Fránckfort junto al Meno o en Berlín a orillas del lago Wannsee). Y es que la pérdida en el contacto con la naturaleza que supone la vida urbana y laboral hizo renacer el deseo de retorno a la misma: de hecho ahora la piel morena, que presupone el contacto con el aire libre, el sol y la naturaleza o la práctica de algún deporte, se pone de moda y es un signo de distinción. Las clases adineradas pueden permitirse viajar a la isla de Capri, esquiar en los Alpes o pasar unas vacaciones en el lago Wolfgang. Las clases trabajadoras sueñan con tener un trozo de tierra con una pequeña caseta y una pequeña pérgola donde pasar sus ratos de ocio cerca de la ciudad, son los famosos Schrebergarten y, por supuesto, acuden en masa a los baños al aire libre. Muchos textos de las canciones de la época así lo reflejan como por ejemplo en el Schlager "Am Sonntag will mein Süßer mit mir segeln gehn" (1929).

También se produjeron cambios en las costumbres sexuales, consecuencias de los cambios sociológicos y de la proliferación de anticonceptivos (la industria farmacéutica llegó a producir entre ochenta y no-

7 SalvettI, Guido,Historia de música, 10. El siglo XX, Madrid, Turner, 1986, págs. 126-130.

Futhark 8 (2013) Fernández, La influencia del contexto intelectual, 127-151 ISSN 1886-9300 
venta millones de condones anualmente), también se difundieron revistas de contenido erótico y sexual junto con libros y películas. Asimismo se abrieron locales de ambiente homosexual (gay y lésbico) en ciudades como Berlín y Hamburgo entre otras. La nueva mujer se convirtió en un símbolo de la revolución sexual de los años veinte:

"She had short hair, the famed Bubikopf; she was slender, athletic, erotic, and amaternal. She smoked and sometimes wore men's clothes. She went out alone, had sex as she pleased. She worked, typically in an office or in the arts, and lived for today and for herself (...) The woman of yesterday lived for her husband and her children and sacrificed for the family. The new woman believes in equal rights, and strives to be self-reliant in economic terms" 8 .

Las jóvenes protagonistas de las novelas de la autora Imgard Keun ${ }^{9}$, que deambulan por Colonia y por Berlín a finales de los años veinte, son el mejor botón de muestras para entender a esta nueva mujer.

Los EEUU se convierten en un mito, en un país de posibilidades ilimitadas, en meta para decenas de miles de emigrantes, de tal manera que en el 1923 unos 114.000 alemanes ante la miseria imperante se vieron empujados a cruzar el Atlántico.

A nivel internacional destacan los EEUU que en los cuarenta años que siguieron a la Guerra de Secesión (1865) habían conocido un vertiginoso desarrollo económico que los convirtieron en la primera entre las naciones industrializadas. El primer período del imperio estadounidense concluye con el crack financiero del 24 de octubre de 1929 (el famoso Jueves Negro), cuyas raíces se hunden en la política de los años veinte, que se corresponden con la mítica época del jazz. Los años veinte, marcados por un desenfrenado hedonismo y por una convulsa excitación, tienen no sólo el jazz como símbolo de la época, sino el cine, la radio, el prohibicionismo y el gramófono; pero este producto de la cultura afroamericana va indiscutiblemente unido a cada uno de ellos.

El jazz significó para generaciones de blancos en EEUU y en Europa, en las primeras décadas de nuestro siglo, en buena medida una elección cultural de dimensión internacional, rechazando barreras locales y la adhesión al ritmo de vida contemporánea ${ }^{10}$. Naturalmente la industria cultural ha intervenido en ello, siendo la fuente de estas exigencias.

En Europa el histórico colapso de Wall Street desmorona las economías de los países europeos y la lenta recuperación económica iniciada

WEITZ, Erich D.,op. cit. págs.305-307.

9 FERNÁNDEZ MARTÍNEZ, Juan-Fadrique, "Nueva objetividad y violencia de género: las protagonistas de Irmgard Keun", en OROZCO VERA, María Jesús, Literatura, género y violencia, Sevilla, Bienza, 2007.

10 LANZA, Andrea (ed.), Historia de la música, vol. VII, "La crisis de los años treinta", Madrid, El Siglo XX, 1991, pág. 110.

Futhark 8 (2013) Fernández, La influencia del contexto intelectual, 127-151 ISSN 1886-9300 
en 1924 se viene abajo. En Alemania se alcanzan los cinco millones de parados, el comercio internacional se reduce en un $70 \%$ de 1930 a 1933, la producción industrial cae en cuestión de meses en un $15 \%{ }^{11}$. Los efectos políticos e institucionales no son menos profundos: resurgen las viejas políticas proteccionistas, las barreras aduaneras y se produce un incremento de los movimientos nacionalistas.

En las afueras de las ciudades se crearon verdaderos campamentos de parados, el más famoso fue Kuhle Wampe, sobre el cual B. Brecht rodó una película. Al principio de los años treinta era corriente que esta población desamparada viviera acampada en las afueras de la ciudad, sólo con la entrada del invierno regresaban a la misma. El cabeza de familia era el único que iba regularmente a la ciudad a sellar a la oficina de socorro de parados. Existe una canción que lo refleja magníficamente: "Wir zahlen keine Miete mehr" (1932).

El espíritu de revancha contra la paz impuesta, adormecido por la diplomacia del ministro Stressemann, se implantó en Alemania, preparando el camino al nazismo. Alemania se rearma en pocos años, hecho que se vio favorecido por el aislacionismo de EEUU y no obstaculizado por los aliados, que vieron en el régimen de Hitler un freno frente a la amenaza soviética. Las condiciones para el advenimiento de una nueva guerra en suelo del viejo continente se estaban preparando.

La crisis de 1930 trae otras profundas repercusiones sobre la estructura de la organización social: la integración en la ciudad de estratos campesinos, el desarrollo de la clases obreras y de la pequeña burguesía de masas, la concentración de capital, una nueva concepción del estado, es decir, un capitalismo de estado (éste interviene en la gestión económica, en la programación social y en la organización ideológica). El nazismo se corresponde con la exigencia para el capitalismo imperialista y agresivo de crear una estructura estatal de control y de regulación de las fuerzas sociales adecuada a la situación de crisis de 1929. Se genera un despotismo policíaco y unas nuevas formas de organización del consenso, una dualidad autocrática y de masas, propia del nazismo y del fascismo, que impiden tomar conciencia al mundo político e intelectual de la auténtica naturaleza de estos regímenes. Los intelectuales, con la excepción de la escuela de Fráncfort, son escasamente conscientes del alcance de los acontecimientos.

Pero lo que confiere a los años treinta un particular significado histórico es la consolidación en Europa de esa realidad social que se conoce con el nombre de «sociedad de masas», como forma dominante de difusión de cultura. Por eso merece una especial atención el estudio de los mass media y a su influencia en las formas de consumo musical contemporáneo, que preocupó a los filósofos reunidos en torno al Insti-

11 LANZA, Andrea, ibid., págs. 16-34.

Futhark 8 (2013) Fernández, La influencia del contexto intelectual, 127-151 ISSN 1886-9300 
tuto para la Investigación Social de Frankfurt (Horkheimer, Adorno, Marcuse y Habermas) ${ }^{12}$.

Otra postura bien distinta se observa con los filósofos neoliberales, como el español José Ortega y Gasset con su famoso libro La rebelión de las masas de 1930 (en el que se emplea el término por primera vez en su acepción moderna), el alemán Karl Mannheim con Mensch und Gesellschaft im Zeitalter des Umbaus (1935) y Hannah Arendt Elemente und Ursprünge des Totalitarismus $(1951,1955)$, ven con sus teorías el germen primero de toda degeneración totalitaria en el ascenso de las multitudes. A medios como al periodismo se les atribuyen una responsabilidad directa como instrumentos de presión ideológica y de propaganda política frente a un público vasto e indefenso. Estos autores desprecian la cultura de masas, dejando entrever un odio hacia toda forma de igualitarismo y la nostalgia por épocas aristocráticas en las que los valores de la cultura eran un bien de clase al que no todos tenían derecho.

Se sancionan ideas anteriores como por ejemplo Freud y su teoría del psicoanálisis, Wittgenstein y sus investigaciones sobre el lenguaje lógico-matemático tienen más peso académico, asimismo sigue presente la dodecafonía de Schönberg.

La preeminencia que adquieren en la Alemania y en Austria los problemas sociopolíticos conlleva una revalorización de la realidad (sociopolítica) frente al mundo onírico e individualista. No irrumpe de repente, también en la estética expresionista habían hallado eco los problemas de índole social, o la problemática cotidiana en las grandes ciudades. La tendencia a difundir entre el público las obras de la vanguardia, a mediados de la década de las experimentaciones y rupturas había concluido. La vitalidad cultural se mantiene en la década de la inflación, pero el debilitamiento de la energía creativa se irá generalizando y es hacia 1924-1925 cuando tiende a normalizarse.

El Novembergruppe ${ }^{13}$ propugna el compromiso políticorevolucionario de los artistas, la unión entre el individualismo del Expresionismo y el nuevo compromiso político de posguerra son definitivos y a él se adhiere el pintor expresionista Max Pechstein. Muchos artistas fueron testigos directos de la guerra de ahí que el subjetivismo individualista se hiciera impracticable ante la realidad revolucionaria, la miseria y las perspectivas socialistas. Pero en torno a 1920 se decretó la

12 La toma de conciencia intelectual en música toma el nombre de Adorno, aunque la autoridad de éste no dejó de ser discutida ya en los círculos musicales de vanguardia de la posguerra. Los trabajos de Th. W. Adorno "Schlageranalysen" (1929) y su posterior "Musikalische Warenanalyse" (1955) son muy relevantes para conocer su pensamiento acerca de la música utilitaria.

13 Noviembre fue el mes en que cayó el emperador Guillermo II y cuando se produjo la derrota militar.

Futhark 8 (2013) Fernández, La influencia del contexto intelectual, 127-151 ISSN 1886-9300 
muerte del Expresionismo y se anunció un nuevo movimiento conocido como Neue Sachlichkeit ${ }^{14}$, como reacción a la subjetividad expresionista y a la politización de la literatura. Desde el punto de vista de los géneros, la guerra había hecho usual el estilo del reportaje representativo de este movimiento que pretende ser una fiel transcripción de la realidad y de la fotografía. Sin embargo el Expresionismo, como grotesca deformación de la realidad con objeto de revelar lo trágico, tiene vitalidad y continuidad en la posguerra siendo el papel de Berlín preeminente.

El fundador de la Bauhaus ${ }^{15}$, W. Gropius, cree que el artista debe contribuir a la construcción de un mundo mejor y más racional, para ello el artista tiene que edificar, convertirse en artesano y constructor de objetos de la vida diaria, desde los pequeños objetos del hogar a la ciudad. Pretende así romper la separación entre artesano y artista, y sobre todo del artista individual encerrado en su propia genialidad, por ello propone formar una comunidad para crear juntos. Estas bases ideológicas acerca de la vida y del artista y de su praxis en el contexto de la República de Weimar chocan con el sistema económico-productivo que busca el máximo beneficio.

Asimismo en el ámbito de la pintura hay que nombra a Grosz con sus pinturas y dibujos que denuncia el militarismo, la burocracia y la miseria de las masas urbanas, y a Otto Dix, que animó al grupo dadaísta berlinés. Ambos pintores fueron los que en el ámbito de la pintura de forma programática anunciaron el final de la subjetividad, apartándose del grupo Dadá e incorporándose a la Nueva Subjetividad. Este grupo a partir de 1918 denunció la represión de la República de Weimar contra los espartaquistas a quienes apoyaba directamente. Hacia 1924-1925 aparecen las últimas manifestaciones del Expresionismo alemán, el movimiento dadaísta agota las experiencias vanguardistas y el grupo surrealista (cuyo primer manifiesto era de 1924) hacia 1930 deja de existir como movimiento organizado.

En Berlín, cuartel general del teatro y el cabaret político, destacan figuras como Otto Reutter, Erwin Piscator y Max Reinhardt. Su actividad

14 Nueva Objetividad se convirtió en moda intelectual y cultural entre 1924 y 1933 , como forma de hacer una literatura más objetiva, una literatura para mantener informada a la opinión pública sobre aquellos aspectos que los medios silenciaban. Sobre la vigencia de esta corriente literaria no hay una opinión unánime, se le puede hacer coincidir prácticamente con la República de Weimar. El primer grupo surge en torno a 1920, pero será en 1924 cuando surja el nombre. Cfr. MALDONADO, Manuel; MonTESINOS, Manuel, La literatura alemana a través de sus textos, Madrid, Cátedra, 1997, págs. 893-894.

15 Escuela de arquitectura y, por extensión, de diseño y de artes plásticas fundada en Weimar por W. Gropius en 1919, trasladada a Dessau en 1925 y disuelta en 1933 tras su ubicación en Berlín. Es el intento más eficaz de nuestro siglo de conjugar arte e industria. Cfr. SuREDA, Joan; GuARSCH, Anna María, La trama de lo moderno, Madrid, AKAL, 1987, pág. 176.

Futhark 8 (2013) Fernández, La influencia del contexto intelectual, 127-151 ISSN 1886-9300 
disminuye a partir de 1929 obligados por el terror nazi y en 1930 todo el país se ve inundando ya de propaganda hitleriana. La continuidad del Expresionismo estaba garantizado en 1918 por la actividad del teatro Das junge Deutschland, abierto por Max Reinhardt, y por el teatro experimental de Lothar Schreyer. Asimismo Piscator funda en 1919 el «Teatro Proletario» para sustituir al teatro burgués, su objetivo era instruir y educar.

Sobresale en literatura el expresionista Ernst Toller con la preeminencia del tema socio-político sobre el existencial-individual. La temática de sus dramas es la del hombre en términos existencialistas pero dentro de la sociedad capitalista e industrial que tiende a anularlo y a convertirlo en máquina.

El compromiso político del artista está representado por figuras del teatro como Erwin Piscator, punto de referencia obligado para B. Brecht y para Gropius -arquitecto y urbanista-, y para el grupo de músicos que trabajaron con ellos. En Piscator reaparece el tema de la obra de arte total (Gesamtkunstwerk), todas las artes unidas con una intención político-educativa bajo una perspectiva marxista. Se establecen así las bases para un contacto entre la música y el resto de las artes.

La dramaturgia de Brecht que se inicia en Berlín en 1924, está en conexión con las ideas de Piscator y con sus soluciones formales. En la relación entre espectáculo y espectador, cuando Piscator habla de «implicación racional» del espectador, Brecht habla de disociación entre los diferentes elementos para que la crítica del espectador sea posible. El teatro tradicional, aristotélico o «ilusionista» encontrará una salida extraordinaria en el cine de Hollywood, es más convincente en tanto en cuanto hace olvidar que estamos ante una ficción; Brecht lo sustituye por un teatro que debe evitar en todo momento que el actor se identifique con el personaje, ni el escenario con la acción. Este teatro «épico» se acerca a los fines racionales perseguidos por la Bauhaus: pretende hacer pensar.

En la narrativa no aparecen grandes nuevos horizontes, sino que se sigue por los derroteros surgidos antes de la guerra, se da una inclinación retrospectiva examinando los acontecimientos a la luz de los nuevos elementos de juicio. Destacan las siguientes obras: Das Schloß (1921/1922) de F. Kafka, Der Zauberberg (1924) de Th. Mann, la extensa novela Der Mann ohne Eigenschaften I y II (1930 y 1933) de Robert Musil y la trilogía Die Schlafwandler (1931-1932) de Hermann Broch entre otras. En ellas la memoria tiende a examinar más el pasado que el presente, la caracterización de una época de la que se pretende hacer balance. No obstante según Fritz Martini con Berlin Alexanderplatz (1929) «Döblin proporcionó algo esencialmente renovador a la técnica

Futhark 8 (2013) Fernández, La influencia del contexto intelectual, 127-151 ISSN 1886-9300 
de la novela alemana de este siglo [el XX]» ${ }^{16}$, su autor se revela maestro para armonizar la novela a partir de la refinada técnica del montaje.

Franz Biberkopf, el personaje de la novela, retoma el pulso a las calles de Berlin en el 1928 y 1929 tras salir de la cárcel. En este collage aparecen alusiones a los Schlager del momento, por ejemplo "Mein Papagei frißt keine harte Eier" (1927) de W. Kollo y H. Frey o la actuación de Raquil (por Raquel Meyer) en Berlín y su célebre interpretación de "La violetera".

También son característicos de la República de Weimar los textos poéticos con intencionalidad satírica, muchos presentados en el cabaret político-literario ${ }^{17}$. Entre los autores de esta línea destacan Erich Kästner, Kurt Tucholsky ${ }^{18}$ y Walter Mehring, sus poemas tratan temas de actualidad, muchos denuncian el militarismo imperante y la opresión social. Como poesía de filiación claramente política encontramos los textos de Erich Weinert, que él mismo recitaba en fábricas o en los mítines del Partido Comunista de Alemania ${ }^{19}$.

La controvertida sociedad de los medios de comunicación de masas de la República de Weimar se encuentra polarizada entre dos tendencias de signo opuesto: la denominada «Sowjethoffnung» frente a la llamada «Amerikabegeisterung»:

"Während die Begeisterung für die Sowjetunion sich zumeist aus einem -sehr schnell wieder erlöschenden, auch durch die realen Entwicklungen enttäuschten -humanitären Pathos speiste, wirkte der «Amerikanismus» nachhaltiger $(\ldots)^{\prime 20}$.

Frente al sueño de la igualdad de oportunidades y de la abolición de las clases sociales, crece la ilusión de la superación de los conflictos de clases basándose en el americanismo como promesa de futuro a través de una mejora de la sociedad capitalista. Esta última esperanza radicaba en la relativa buena posición económica de los trabajadores americanos y en los pronósticos de la incorporación de una técnica racionalizadora que contribuyera a mejorar las condiciones de vida, sin recurrir a

16 MARTINI, Fritz, Deutsche Literaturgeschichte, Stuttgart, Kröner, 1977.

17 Cfr.RIHA, Karl, "Kabarett" (págs. 219-224) en Deutsche Literatur. Eine Sozialgeschichte (tomo 9 Weimarer Republik - Drittes Reich: Avantgardismus, Parteilichkeit, Exil 1919-1945) y "Kabarettkultur" (págs. 94-106) en Einführung in die deutsche Literatur des 20. Jahrhunderts (tomo. 2 Weimarer Republik, Faschismus und Exil).

18 Kurt Tucholsky (1890-1935) utilizó Ilamativos pseudónimos: Peter Panther, Theobald Tiger, Ignaz Wrobel o Kaspar Hauser.

19 Eisler puso música a muchos de estos poemas que fueron cantados por Ernst Busch. Weinert, exiliado, participó en la Guerra Civil española a favor de la república.

20 SCHÜTZ, Erhard; VOGT, Jochen, Einführung in die deutsche Literatur des 20. Jahrhunderts, tomo 9 , pág. 22.

Futhark 8 (2013) Fernández, La influencia del contexto intelectual, 127-151 ISSN 1886-9300 
la temida revolución. De tal modo que en los años de bonanza económica de la República de Weimar "etablierte sich eine Kultur, die durch und durch von amerikanischen Einflüssen durchdrungen war, sei es in der Sportbegeisterung (Boxen!), sei es im Jazz, sei es in der Varietät-Show oder im Musical"21.

Otro de los representantes de la cultura de masas de esta época es el cine. Ya en 1912 la producción cinematográfica puedo haber sido sonora, pero habrá que esperar hasta 1926 cuando la casa Warner presenta la primera película sonora Don Juan, al año siguiente The jazz singer, de Alan Crosland será la primer película sonora y hablada. Su retraso se debe al miedo de las empresas cinematográficas a perder su hegemonía comercial en el campo internacional, debido al carácter específico de las lenguas nacionales. La Warner Brothers en los EEUU, al borde de la quiebra, no tuvo más remedio que lanzarse como medio para seguir a flote. Con la crisis de 1929 se necesitan nuevas motivaciones para atraer al público hacia las salas a pesar de las penurias de la época. La nueva situación política y económica favoreció la concentración de empresas y la formación de enormes monopolios en el ámbito de los mass media. En este contexto la música de películas comienza su auténtica historia. Es necesario tener en cuenta que el cine no está sometido sólo a la industria capitalista de la cultura, sino que también será un instrumento de propaganda política y formador de conciencias de primer orden.

El cine se había desarrollado poderosamente en Alemania ya durante la Primera Guerra Mundial, Erich von Ludendorff hizo que el estado invirtiera grandes sumas de dinero para fundar la Ufa. El cine alemán fue dejando de importar películas y era capaz de producirlas rápidamente y en grandes cantidades. Las películas sirvieron en la guerra más que nunca para entretener, distraer y como medio propagandístico.

En este punto es necesario también recordar que el cine expresionista alemán, con una temática propia de la posguerra, pero con una fotografía alucinada y deformante propia de la primera etapa del Expresionismo, se difundió por todo el mundo 22 .

El uso de la música en el cine mudo durante las tres primeras décadas se valía de sus posibilidades alusivas para lograr efectos descriptivos y onomatopéyicos. Los estrenos eran con orquesta, en sesiones sucesivas generalmente un arreglo para piano de la versión orquestal, aunque algunas tenían música expresamente compuesta para ellos. En la mayoría de los casos se hacía de forma casual, existían antologías o

21 Idem.

22 Der Golem (nueva versión de 1920) o El gabinete del doctor Caligari (1920) con su simbología relativa a la monstruosidad del mundo contemporáneo son dos buenos ejemplos.

Futhark 8 (2013) Fernández, La influencia del contexto intelectual, 127-151 ISSN 1886-9300 
repertorios adecuados a las diferentes situaciones fílmicas ${ }^{23}$. El acompañamiento se debe al fenómeno de integrar el cine dentro de los espectáculos tradicionales, así se opta por el piano en vez de por el disco. Se trataba de englobar al cine en la tendencia que caracterizaba al espectáculo teatral. Pero la llegada del cine sonoro hará que este espectáculo de masas se desarrolle en la dirección opuesta, es decir, adquiere un carácter de cotidianidad otorgado por «el hablado».

Al principio el cine sonoro, que toma como modelos los de la ópera, el ballet o el teatro o el espectáculo musical tradicional, prevé el cine sonoro sólo para las partes musicales cantadas. Así El cantor de jazz integra la trama narrativa en el marco de un repertorio de piezas exitosas de jazz. La vanguardia en la década de los veinte se vuelca en el cine. Pero la evolución del lenguaje cinematográfico emprende un camino muy distinto al de las teorías vanguardistas. A lo largo de los años treinta y en la posguerra hasta los sesenta el gran cine de masas evolucionará bajo los designios de Hollywood y sus estrellas. ${ }^{24}$ Incluso la literatura de los últimos años de la República de Weimar es inimaginable sin la existencia del cine: "Schon ihre Versuche in der Montagetechnik leiten sich direkt aus der Absicht her, den Film literarisch zu imitieren". 25

En los EEUU el jazz fascinó a los compositores estadounidenses de la época que terminaron incorporándolo a sus creaciones, es el caso G. Gehrswin, autor de Rhapsody in blue (1924) y de Un americano en París (1928). La era del jazz asistió a la agudización del problema racial en el Norte, relacionado con la gran inmigración interna de los estados del Sur y la creación de guetos negros en las grandes ciudades. Se popularizó la moda del negro entendido como personaje exótico y los blancos sintiéndose amenazados reaccionaron tratando de apropiarse del nuevo idioma musical y surge "el jazz blanco», que provocaría a su vez reacciones de distinta índole, algunas desembocan en la afirmación de la negritud con la agresividad del blues. El autor estadounidense contemporáneo, F. Scott Fitzgerald bautizó a esta época como Jazz Age.

Antes de la irrupción del jazz en Alemania, existen muchos aspectos que son necesarios comentar. En primer lugar es imprescindible indicar que tras la Gran Guerra, la antigua música militar o Marschmusik no desaparece ni en Alemania ni en Austria, sobre todo teniendo en cuenta

23 Becce, Giuseppe; ERdmann, Hans, Allgemeines Handbuch der Film-Musik, Berlin, Schlesinger'sche Buchhandlung, 1927, célèbre manual para pianistas de películas. Asimismo fue famosa la Enzyklopädie de E. Rapée, que ofrecía un código en forma de asociaciones estereotipadas entre personajes tipo (el ladrón, el don Juan, etc.) con determinados modelos musicales. En otros casos se escogían piezas musicales célebres y se integraban en el contexto de la situación fílmica.

24 En los años treinta la pareja de moda en el cine alemán está compuesta por la inglesa y rubia Lilian Harvey y por su partenaire Willi Fritsch.

${ }^{25}$ SCHÜTZ, Erhard; VOGT, Jochen, op. cit.pág. 17.

Futhark 8 (2013) Fernández, La influencia del contexto intelectual, 127-151 ISSN 1886-9300 
que muchos de los intérpretes y autores permanecen (caso de los compositores Franz Lehár ${ }^{26}$ o Leo Fall ${ }^{27}$ ). Aunque con la República se quiso decir adiós para siempre al mundo feudal que suponía la época guillermina, en sus operetas persistían como protagonistas las princesas, príncipes, barones, húsares, oficiales, marquesas y jovencitas de la época anterior, un mundo cuajado de elegantes damas locamente enamoradas de sus seductores galanes, a menudo oficiales, que bailaban y coqueteaban en los elegantes salones de un mundo aristocráti$\mathrm{Co}^{28}$. Muchos compositores y artistas procedentes del decadente imperio austro-húngaro emigran al prometedor Berlín, capital de un estado mucho mayor, con mayores expectativas profesionales. En el otoño de 1919 mientras la población pasaba verdaderas calamidades para poder sobrevivir se estrena la opereta Ballnacht, también se volvieron a representar las operetas (Fürstenoperetten) de Oskar Strauß.

Consecuencia directa de la guerra fue la pérdida de las colonias de ultramar de tal forma que ahora sólo quedan como sueños exóticos ${ }^{29}$ los ofrecidos en el mundo del Schlager y de la revista: los calurosos trópicos con sus bailes mulatos y las sensuales bailarinas en el harén interpretando la danza del vientre eran de lo más $i^{30}$. Josephine Baker personifica el art déco con su exotismo y erotismo. A mitad de los años veinte subió al escenario parisino interpretando a las nativas de la jungla africana con falda de bananas y una versión libre del charlestón, personificando el eclecticismo del período de entreguerras. Pero este conti-

26 Franz Lehár (1870 Komárón -Hungría-, 1948 Bad Ischl -Austría-): estudió en Praga. Autor de "Die lustige Witwe" (1905) y "Das Land des Lachens" (1929) famosas operetas. Evergreens: "Da geh ich ins Maxim" (1905), "Wolgalied" (1927), "Schön ist die Welt" (1930) entre otros. En Das Lexikon des deutschen Schlagers, München, Piper-Schott, 1993, págs. 204-205.

27 Leo Fall (1873 Olmütz -Bohemia-, 1925 Viena): Estudió en Viena, despues se marcha a Berlín como director de orquesta, a Hamburgo y a Colonia. A partir de 1906 Vivió en Viena. Autor de Evergreens como: "Dollarwalzer"(/1907) y "Rose von Stambul" (1916), en Das Lexikon des deutschen Schlagers, ibid. p.119.

28 Cfr. SPERR, Monika, op. cit. pág. 88.

29 Cfr. ReIF,Wolfgang "Exotismus und Okkultismus" (págs.155-167) en Deutsche Literatur. EineSozialgeschichte (Bd. 9) de H.A. Glaser: "Unter dem Begriff Exotismus wird eine Haltung verstanden, die -idealtypisch gesehen- die Komponenten Zivilisationsflucht, Hinwendung zu und Begegnung mit abenteuerlicher Ferne, exotischer Natur und/oder Kultur, daraus resultierende Erfahrung des Ich, der eigenen Kultur und Ihre Kritik umfaßt (pág 155). Asimismo el artículo de Willy Seidel "Exotismus in deutscher Literatur" publicado en 1928 in Der Kunstwart (1928), $n^{\circ} 41$, págs. 148-153, ofrece reflexiones coetáneas aunque sobre el ámbito de lo literario.

30 "Ausgerechnet Bananen"(1923) de Josephine Baker representante genuino para el ambiente tropical, el tango "Leila" (1928) o refleja la ambientación oriental, o los términos "orientalisches Lied und Foxtrott" para definir el género de pertenencia de la canción "Salome" (1920) son tres ejemplos de lo mencionado anteriormente.

Futhark 8 (2013) Fernández, La influencia del contexto intelectual, 127-151 ISSN 1886-9300 
nuísmo es tan sólo parcial ya que como afirma Sperr: "Der deutsche Schlager suchte Anschluß an die Wirklichkeit, wurde realitätsbewußter. Die dem Expressionismus folgende «neue Sachlichkeit» veränderte auch ihn"31

Las estrellas de los años veinte son legendarias, intérpretes de la opereta como el tenor Richard Tauber, la diva del teatro Fritzi Masary y la estrella del cabaret y de la revista Claire Waldoff. Al mismo tiempo es la época del esplendor de los Kinos Paläste (Gloria-Palast, Lichtspielpalast, Ufa-Filmpalast). A pesar de ser el cine todavía mudo era una gran competencia para los espectáculos de variedades, otros espectáculos de feria o los pequeños locales de baile.

Los antiguos locales donde se bailaba se renovaron con el impulso de los nuevos ritmos estadounidenses: foxtrott y shimmy. Estos dos ritmos rápidos trajeron consigo toda una serie de elementos de moda (zapatos shimmy, corte de pelo shimmy, etc.). Norteamérica se pone de moda, todo lo bueno parece proceder de allí: la cadena de montaje de fabricación, los grandes anuncios luminosos, los coches Ford, técnicas radiofónicas, sus películas, la música, etc.

Con la canción "Ausgerechnet Bananen "(1923) ("Yes, we have no bananas"), con letra en su versión alemana de Beda ${ }^{32}$, se puede ubicar el comienzo a gran escala de la primera invasión de música de entretenimiento norteamericana. Hasta este momento las composiciones alemanas y austríacas habían resistido la fuerte competencia de ultramar, pero a partir de este momento para alcanzar el éxito las composiciones han de tener un carácter cosmopolita. Lincke no consigue adaptarse a los nuevos modelos de creación, quienes sí lo logran son Gilbert ${ }^{33}$ y Kollo ${ }^{34}$. El Schlager alemán se internacionaliza, como se internalizó muchos otros aspectos culturales. A este respecto Weitz señala: "The electrified and reproducible sound and image internationalized cultura in the 1920 s as never before, and inspired and worried people all across the social spectrum"35.

31 SPER, Monika: op. cit. pg. 88.

32 Seudónimo de Fritz Löhner, uno de los letristas más importante de toda la historia del Schlager. Nació en 1883 en Wildenschwert (Bohemia) y murió en Auswitz en 1942. Vid. Lexikon des deutschen Schlagers, p. 69.

33 Jean Gilbert (seudónimo de Max Winterfeld) lo hemos citado en el período anterior como compositor de operetas de gran éxito, de entre sus canciones destacan: "Puppchen , du bist mein Augenstern" (1912) y "Durch Berlin fließt immer noch die Spree" (1925). Vid. Lexikon des deutschen Schlagers (p. 136).

34 Walter Kollo nació en Neidenburg (Prusia Oriental) en 1878 y murió en Berlín en 1940. Otro grande de la historia del Schlager. Compositor de innumerables canciones, entre ellas destacamos: "Immer and der Wand lang" (1907), "Warte, warte nur ein Weilchen" (1923), "Das ist der Frühling in Berlin" (1924). Vid. Lexikon der deutschen Schlagers, págs. 190-191.

35 WEITZ, Eric D., op. cit., pág. 250.

Futhark 8 (2013) Fernández, La influencia del contexto intelectual, 127-151 ISSN 1886-9300 
La música de jazz ${ }^{36}$ que llegó a Europa tras la Primera Guerra Mundial desde los EEUU, convertidos en la primera potencia mundial, era un producto que ya se había hecho comercial, que era querido he interpretado por músicos blancos como música de baile, de entretenimiento o apta para conciertos. Pero sin embargo el jazz suponía una revolución musical, conservaba en sus derivados muchos de sus rasgos originales: espontaneidad e improvisación, catalogados por algunos como elementos salvajes («barbarische Urwaldstänze»). Su capacidad de atracción fue reconocida rápidamente por los círculos amantes del autoritarismo, entre ellos el nazismo, de tal manera que en seguida se comenzó a hablar con miedo acerca de la contaminación de la juventud alemana. Está música es perseguida por ejemplo por uno de los grupos empresariales mediáticos más importantes de la época: el Hugenberg-Konzern (con importantes ramificaciones en la prensa y en el cine, y cuyo presidente llegó a ser en un primer momento ministro con Hitler). El relevo será tomado pronto por los nazis con su bilioso «artfremden Niggerjazz» ${ }^{37}$.

Igual que el tango, que se había abierto camino en los salones de Londres y de París, el jazz atrajo primero a las generaciones más jóvenes, a un público cosmopolita, no provinciano y weltoffener. A comienzos de los años veinte estos círculos mundanos estaban por el amor libre, se afeitaban las cejas, esnifaban cocaína, eran señores y señoras «de mundo». Del mismo modo que la moral se hizo cada vez más liberal, la falda se hizo cada vez más corta, e igualmente el cabello se cortaba cada vez más corto ${ }^{38}$. Esta imagen divertida y extravertida se corresponde con la imagen de los años veinte de una determinada élite, sin embargo las condiciones de vida de la mayoría de la población eran por el contrario bastante difíciles. Para sobrevivir ésta recurre muchas veces al humor ácido o negro, así algunas canciones que contenían vagas esperanzas en sus textos son parodiadas agriamente ${ }^{39}$.

La canción compuesta para el carnaval de Colonia "Wir versaufen unsrer Oma ihr klein Häuschen" por Robert Steidl (compositor y letrista) en el año 1922 se convirtió en un auténtico himno en toda Alemania y representa claramente el espíritu de la época de la inflación. El Schlager comenzó a cantar las necesidades de la gente, no en sus aspectos más

36 Los ritmos americanos de baile más importantes fueron: cakewalk, shimmy, charleston y foxtrott.

37 Para un análisis extenso sobre diferentes aspectos de la historia social y la repercusión de la cultura del baile durante la República de Weimar vid. Der Schlager und seine Tänze im Deutschland der 20er Jahre, (Zúrich, Chronos, 1991)de Christian Schär.

38 El corte de pelo denominado Bubikopf o Pagenkopf se puso de moda: a la altura de las orejas y en la frente el flequillo caía liso y recto.

39 Vid. SPERR, Monika: op. cit., pág.94.

Futhark 8 (2013) Fernández, La influencia del contexto intelectual, 127-151 ISSN 1886-9300 
prosaicos lógicamente. La realidad circundante no aparecía en toda su crudeza, pero evitarla totalmente tampoco era posible o apropiado, aunque obviamente ofrecía menos garantía de obtener futuros beneficios. Otro ejemplo muy significativo representa la canción "Pleite - pleite" (1924) donde alegremente se canta el hecho de que nadie tenga un duro.

El primer cosmopolita de la opereta fue Franz Lehár, también lo fue Jacques Offenbach con sus chistosas operetas que imitan las novedades de París, junto a ellos aparece la figura de Paul Lincke, que continua sus viejos moldes imperiales. Lehár mezcló la música de salón internacional con elementos del folclore nacional, de ahí que su música gustase a la alta sociedad, sus operetas presentan melodías cargadas de gracia, llegando hasta el sentimentalismo, pero libres de elementos jazzísticos provenientes de la calle. Franz Lehár alcanza importantes triunfos con: Paganini, Zarewitsch, Das Land des Lachens y Das Wolgalied. Como cantante de estas operetas destaca la figura de Richard Tauber.

La estrella femenina de la época es Fritzy Massary ${ }^{40}$, la diva de la opereta de los años veinte, con elevadísimo caché. Pronto refulge también la figura de Claire Waldoff ${ }^{41}$. Otra figura destacada fue Hans Albers ${ }^{42}$, que comenzó interpretando personajes bufos en la opereta, para triunfar definitivamente en el cine.

Pero los tiempos de la opereta empezaban a declinar y W. Kollo conoció la época de esplendor así como la decadencia del género. Éste se dedicó a componer Schlager cada vez más exitosos y comerciales conjuntamente con Hermann Frey (letrista). Ambos son autores de una canción que se convirtió en el himno de los amantes de la borrachera "Immer an der Wand lang!"(1907) y de otros éxitos posteriores como "Bummel-Petrus"(1920) y "Mein Papagei frißt keine harten Eier" (1927). Tras la guerra, después de atravesar una racha de estrepitoso fracaso económico en sus negocios como empresario teatral, será contratado

40 Fritzi Massary nació en Viena (1882) y muere en Beberly Hills (1969), fue la reina de la opereta de los años veinte. Entre sus muchos éxitos destaca Josef, ach Josef, was bist du so keutsch", Vid. Lexikon des deutschen Schlagers, p. 221.

41 Claire Waldoff (Clara Wortmann) nace en Gelsenkirchen en 1884 y muere en Bad Reichenhall en 1957, cantante y estrella de la revista cantó numerosas BerlínLieder, sobre todo compuestas por W. Kollo, entre ellas destaca "Hermann heeßt er". Vid. Lexikon des deutschen Schlager, p. 314.

42 Hans Albers: Hamburg-St. Georg (1891) - München (1960). Actor y cantante, por su modo de cantar personifica el romanticismo marinero del mar del Norte. Entre otras canciones destacamos:

"Hoppla! Jetzt komm' ich" (1932), "Auf der Reeperbahn nachts um halb eins" (1936), "Goodbye, Jonny" (1939)"Kleine weiße Möwe" (1952), etc. Vid. Lexikon des deutschen Schlagers, pág. 52.

Futhark 8 (2013) Fernández, La influencia del contexto intelectual, 127-151 ISSN 1886-9300 
como compositor para las monumentales revistas de Hermann Haller (director de teatro, libretista y letrista) en el Admiralpalast. Siguiendo el patrón norteamericano y de forma similar a los espectáculos mostrados en la gran pantalla el escenario se llena de cientos de muslos al desnudo de las show-girls, de fabulosos, brillantes y atrevidos vestidos; en cuanto a la música melodías de baile y ritmos de marcha se escuchan con gran estrépito.

El Berlín del mundo de las revistas no tiene nada que ver con el Berlín que aparece en las novelas de Hans Fallada o en el Teatro Proletario de Erwin Piscator, ni con las canciones que al final de los años veinte cantaba Ernst Busch. El Berlín de los trabajadores -así como el de los parados- no era mostrado en las revistas. Lo que aparece es un Berlín de alto estánding, con una agitada vida social.

A mitad de los años veinte, antes de la caída en la grave crisis económica mundial, se pusieron de moda las canciones nonsens ${ }^{43}$, es decir, canciones cuyos textos eran absurdos y en los que primaba el gusto por el disparate -resaltado sobre todo gracias el empleo de la rima final-. Dentro de este género destacaron la díada Kollo-Frey juntamente con Beda (Fritz Löhner). Estos Nonsens-Schlager ofrecen a menudo una lectura picante o en otros casos meramente dadaística. Su correlato sociohistórico se haya entre la inflación y la crisis económica mundial. Estos textos pueden ser aparentemente incoherentes (como la prosa futurista, la poesía surrealista o el flujo de conciencia), pero su unidad o coherencia se apoya en un enunciado performativo del tipo "es necesario interpretar estas frases inconexas como pensamientos de $X$ en la situación $Y^{\prime \prime 4}$.

La prosperidad de los años 1925-1926 benefició por supuesto también a la industria musical, donde las mejoras técnicas fueron constantes, así a partir de 1925 comenzó la técnica de grabación electrónica para la industria discográfica. El Schlager "Die schöne Adrienne hat eine Hochantenne" (1925) es un ejemplo del optimismo en los avances técnicos de la época que se refleja en las canciones.

Un grupo que también causó sensación en la época fueron los Comedian Harmonists ${ }^{45}$, fundado en 1928 , conjunto vocal que tenían como modelo el cuarteto estadounidense Revellers. Tenían un repertorio muy

43 En alemán se conocen como Quatsch- o Nonsenslieder, ejemplos "Was macht der Maier am Himalaya"(1926), "Mein Papagei friß keine harten Eier"(1927), "Tante Paula liegt im Bett und isst Tomaten"(1928), "Meine Mama war aus Yokohama" (1930). BARDONG, Matthias: op. cit., págs. 16-17. menciona algunos ejemplos más de este tipo de canciones.

44 Segre, Cesare: Principios de análisis del texto literario, Barcelona, Editorial Crítica,1985, pág.46.

45 Entre sus éxitos destacamos: "Veronika der Lenz ist da" (1930), "Das ist die Liebe der Matrosen" (1931) y "Schöne Isabella von Kastilien" (1932).

Futhark 8 (2013) Fernández, La influencia del contexto intelectual, 127-151 ISSN 1886-9300 
amplio: Schlager, canciones populares e incluso fragmentos de ópera como la obertura de Der Barbier von Sevilla. El grupo, de origen judío, se disolvió a mediados de los años treinta forzados por las circunstancias políticas ${ }^{46}$.

En el año 1930 surgió una estrella muy importante en el panorama artístico alemán, Marlene Dietrich, que era la protagonista de la película Der blaue Engel, interpretando algunas canciones de Friedrich Hollaender (Ich bin die fesche Lola, Ich bin von Kopf bis Fuß auf Liebe eingesteIIt). Dotada de una gran sensualidad supo conciliar en sus canciones la frivolidad con la tendencia sentimental, enseguida se convirtió en una estrella mundial.

La opereta estaba moribunda tanto musicalmente como desde el punto de vista del contenido, los nuevos compositores y letristas no fueron capaces de infundirle nueva vida. Aunque se anunciaron nuevas "Sensationsoperetten» (como "Im weißen Rössl” de Ralph Benatzky), la opereta con la Primera Guerra Mundial, había sido tocada de muerte, y ésta se da de forma definitiva a lo largo de los años veinte. Su muerte no se debe sólo a la introducción de los nuevos medios sino a los rasgos obsoletos del género.

Así B. Brecht und K. Weil con su Dreigroschenoper (1928) y Aufstieg und Fall der Stadt Mahagonny (1929) escapan de las estrecheces del género, de las normas impuestas por la industria de entretenimiento. En estas obras la música contribuye al distanciamiento del drama, la interrupción de los diálogos y la acción, el comentario, rompen la ilusión escénica. En la primera ópera brechtiana, con su representación de los bajos fondos londinenses, su fuerza moral radica en la invitación a «no juzgar». No sólo se acercan a la música de baile de moda, sino que hunden sus raíces en la vieja obra Bettler-Oper (de Johann Christoph Pepusch y John Gay) escrita como parodia de la ópera cortesana existente hacía doscientos años. Su argumento realista, sus diálogos ácidos y sarcásticos, su denuncia de la pobreza del conocido como Lumpenproletariat (mendigos, prostitutas, vagabundos) y de la injusticia social y, por supuesto, las canciones populares que insertan ${ }^{47}$, causaron sensación en la época. Brecht/Weil se acercaron mucho a la música de consumo comercial, de tal forma que ellos mismos denominaron sus can-

46 Parte de los componentes fundaron entonces el Meistersextett, este grupo fue acusado en 1941 de "entartet» y sus componentes se vieron obligados a emigrar a los EEUU, su desaparición es ejemplo del final de toda una época dorada desde el punto de vista musical que se acabó violentamente.

47 Entre todas destaca "Mäcki-Messer-Song", que se convirtió en un hit mundial. Desde entonces ha habido múltiples interpretaciones, entre otras destacan las de B. Brecht, Lotte Lenya-Weill, Ernst Busch, Louis Armstrong, Ella Fitzgerald, Hildegard Knef y Curd Jürgens.

Futhark 8 (2013) Fernández, La influencia del contexto intelectual, 127-151 ISSN 1886-9300 
ciones con el término "Songs», pero el mundo que mostraban era el ocultado hasta ahora.

M. Sperr al respecto de estas obras señala: "Die waren eine Mischung aus Jazz, Gassenhauer, Moritätengesängen, karikierender Opern- bzw. Operettenparodie. Diese Lieder waren nicht für Sänger, sondern für Schauspieler geschrieben"48. La música de Weil introduce ritmos de tango, de foxtrot, de shimmy, sin esconder su vulgaridad, sino subrayándola y con conscientes deformaciones rítmicas. El encuentro de esta música con este teatro asume un valor expresionista: la vulgaridad se vuelve deforme y repugnante. Las canciones contribuyen a provocar el efecto de distanciamiento que caracterizará a su teatro «épico», así se induce al espectador a reflexionar sobre su propia condición social y no a identificarse con los personajes.

El éxito de esta opereta fue inmediato e internacional ${ }^{49}$, la ira de los nazis se desatará contra esta obra y contra sus autores. Su éxito y repercusión mundiales son parangonables al de fenómenos de aquella época como Rodolfo Valentino o Greta Garbo en la pantalla; el shimmy, el fox, el charlestón, el black bottom o el tango en los locales de baile o R. Tauber y F. Masary en la opereta.

En 1932 como consecuencia de la crisis económica existen en Alemania más de seis millones de parados, sólo una pequeña parte recibe algún tipo de protección, el Schlager obviamente reacciona ante este empobrecimiento de la población. Éste se hace más lento y sentimental, el rápido fox deviene en slowfox lento, el reposado vals inglés se pone de moda, las canciones de éxito deben ofrecer algún tipo de consuelo. Una canción de la época "Schöner Gigolo, armer Gigolo" (1929) nos habla de la decadencia y dura existencia de los antiguos oficiales húsares que ahora han de ganarse la vida como gigolos.

El ritmo de marcha que durante los cortos años del florecimiento económico había sido menospreciado en favor de los agitados y seductores ritmos llegados de ultramar por el público de la gran ciudad rabioso por bailar, vuelve a estar en boga. Este ritmo no se escucha sólo en las calles donde la SS, la SA y el Rotfront en multitudinarios desfiles muestran su fuerza sino en todas partes, y por supuesto también en el Schlager.

Ahora la marcha se impregna de un nuevo carácter, de un sentimiento de fuerza sobre el mundo, el héroe que mejor encarna esta corriente no es otro sino el hamburgués Hans Albers con su "Hoppla! Jetzt komm ICH! Alle Türen auf, alle Fenster auf! Und die Straßen frei für MICH" (1932). En la figura de este cantante se corporeizaba en cierta medida el ideal racial nazi: alto, fuerte, rubio y joven, prototipo en suma del mar-

48 SPERR, Monika: op. cit. pág. 101.

49 El director de cine Pabst la transformó en película en 1931.

Futhark 8 (2013) Fernández, La influencia del contexto intelectual, 127-151 ISSN 1886-9300 
cial nordisch-germanischer Arier. Esto no significa en modo alguno que fuera nazi, simplemente permaneció en el país durante la dictadura y continuó desarrollando su carrera artística, autoafirmándose como apolítico.

En el otro extremo, en el del compromiso político y social, se encuentra Ernst Busch, actor teatral y cantante en cabarets y teatros (entre otros con Piscator en Berlín). Interpretó temas escritos por Brecht, Tucholsky, Mühsam o Kästner, con música de Hanns Eisler ${ }^{50}$. Teniendo en cuenta su resonancia entre las clases trabajadores (y no sólo en Alemania sino en toda Europa sobre todo tras su emigración) habrían de incluirse sus trabajos bajo la denominación de Schlager ${ }^{11}$ por su popularidad sin embargo no es así.

Al mismo tiempo la otra corriente de Schlager, la carente de compromiso político-social, la corriente "sensualista», entretiene y consuela al gran público con la música comercial, mientras que el cine por esas fechas también ofrecía una cartelera donde dentro de un orden idílico Willy Fritsch terminaba consiguiendo siempre a la rubia soñada Lilian Harvey, cumpliéndose así el exigido y genérico final feliz.

Así en 1930, en plena época de crisis económica, los dos éxitos principales fueron "Oh, Donna Clara" (letrista Beda) y "Veronika, der Lenz ist da" (letrista Fritz Rotter). Pues bien en la primera de las canciones, Donna Clara es una bailarina española, protagonista capaz de embrujar con sus arte a un señor, padre de familia de Posen. Un año más tarde en 1931 "Ein spanischer Tango"52 también fue uno de los mayores éxitos del año, su estribillo reza así:

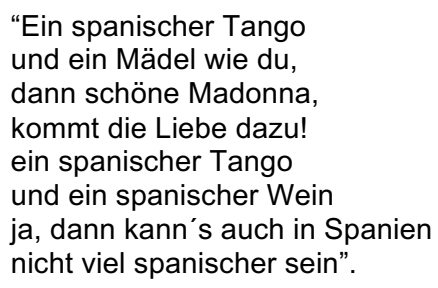

Aquí España es un lugar idílico donde abundan el vino, la música, el baile y las bellas mujeres pasionales. Se trata de un lugar utópico donde

50 Un ejemplo de este «proletarischer Sängen» o Barrikaden-Tauber, como era llamado por sus enemigos, es la famosa "Stempellied" (con letra de David Weber y música de Hanns Eisler), también convirtió en hit la canción "Seifenlied" (letra de Julian Arendt, música de Otto Stranzky).

51 Curiosamente Ernst Busch no aparece inserto en Das Lexikon des deutschen Schlagers, la canción mencionada en la nota anterior tampoco figura en el "Apéndice de títulos".

52 Fue interpretada por L. Frank, letra y música de Walter Jumann y Fritz Rotter.

Futhark 8 (2013) Fernández, La influencia del contexto intelectual, 127-151 ISSN 1886-9300 
refugiarse, un lugar de ensueño que le permite al ciudadano medio escapar de la realidad circundante, o incluso donde fijar sus fantasías sexuales.

En ese mismo año la revista musical Nebenbei bemerkt presentaba a Grete Weiser y a Willi Schaeffers como españoles. Algunos años antes el legendario hit "Valencia" (1925) había alcanzado un enorme éxito como Schlager de temática amorosa y de nostalgia por tierras lejanas ${ }^{53}$ y remite a la primera época tras la inflación, como señala el propio Theodor W. Adorno: "man kann wieder reisen. Valenzia (sic) wird musikalisch das Ausfallstor in alle Ferne für die abgesperrte, verelendete, zerschlagene Bourgeoisie" 54 .

El ritmo del pasodoble también causó furor en esta época en Alemania y junto con el tango, son los dos ritmos español y latinoamericano respectivamente que hacen que muchas canciones inserten tópicos acerca de los español ${ }^{55}$. En estos textos aparecen sobre todo dos figuras que hunden sus raíces en el romanticismo europeo: la díada amorosa formada por el valiente torero conquistador de mujeres y la bailaora española sensual, capaz de levantar grandes pasiones entre el público masculino, dotada de una capacidad amatoria intensa, y como lugar de encuentro de la pareja el ambiente nocturno de la taberna en Madrid, Barcelona o Sevilla fundamentalmente, donde se bebe vino y se baila hasta bien entrada la noche.

No debe olvidarse que la aspiración a una vida plena no sólo se da en países lejanos sino que también se manifiesta en la misma patria y ahí aparece el vastísimo género de los Heimat- y Heimwehschlager ${ }^{56}$. En 1925 el éxito junto a "Valencia" fue "Ich habe mein Herz in Heidelberg verloren", donde en vez de la huida en lo remoto, aparece el reencuentro con el propio país.

Este breve período que aquí he presentado es señalado por muchos como la época dorada de la música comercial alemana y coincide en el tiempo con la inflación (1923), con la crisis económica mundial (1929), con el éxito de las películas musicales sonoras (Tonfilm-Operetten ${ }^{57}$ ) y fue finalmente frenado con la toma del poder de los nazis. Parece como

53 El denominado género de los Fernwehschlager.

54 AdoRno, Th. W.: Schlageranalyse, p. 111, apud Meztger, Gesamtdarstellung, p. 120.

55 FERNÁNDEZ MARTíNEZ, Juan-Fadrique, "La España estereotipada en la canción alemana. Análisis imagológico de 1919 a 1957 " en Sentido figurado. Revista literaria, año 5 , núm. 1 nov./dic.2011, págs.80-89.

56 SCHÄR, Christian: Der Schlager und seine Tänze im Deutschland der 20er Jahre, Zürich, Chronos, 1990. Cfr. pp. 60-61, donde Schär insiste en la misma idea.

57 Dos ejemplos afortunados de este tipo de películas son: Die Drei von der TanksteIle (1930) Der Kongreß tanzt (1931).

Futhark 8 (2013) Fernández, La influencia del contexto intelectual, 127-151 ISSN 1886-9300 